\title{
Genetic Relationships Between Persistency and Reproductive Performance in First-Lactation Canadian Holsteins
}

\author{
B. L. Muir, ${ }^{1}$ J. Fatehi, ${ }^{2}$ and L. R. Schaeffer ${ }^{2}$ \\ ${ }^{1}$ Canadian Dairy Network, 150 Research Lane, \\ Guelph, ON, Canada N1G 4T2 \\ ${ }^{2}$ Centre for the Genetic Improvement of Livestock, \\ Department of Animal and Poultry Science, \\ University of Guelph, ON, Canada N1G 2W1
}

\begin{abstract}
The main objective of this study was to estimate genetic relationships between lactation persistency and reproductive performance in first lactation. Relationships with day in milk at peak milk yield and estimated 305-d milk yield were also investigated. The data set contained 33,312 first-lactation Canadian Holsteins with first-parity reproductive, persistency, and productive information. Reproductive performance traits included age at first insemination, nonreturn rate at 56 $\mathrm{d}$ after first insemination as a virgin heifer and as a first-lactation cow, calving difficulty at first calving and calving interval between first and second calving. Lactation persistency was defined as the Wilmink b parameter for milk yield and was calculated by fitting lactation curves to test day records using a multiple-trait prediction procedure. An 8-trait genetic analysis was performed using the Variance Component Estimation package (VCE 5) via Gibbs sampling to estimate genetic parameters for all traits. Heritabilities of persistency, day in milk at peak milk yield and estimated 305-d milk yield were $0.18,0.09$ and 0.45 , respectively. Heritabilities of reproduction were low and ranged from 0.03 to 0.19 . The highest heritability was for age at first insemination. Heifer reproductive traits were lowly genetically correlated, whereas cow reproductive traits were moderately correlated. Heifers younger than average when first inseminated and/or conceived successfully at first insemination tended to have a more persistent first lactation. First lactation was more persistent if heifers had difficulty calving $\left(r_{g}=0.43\right)$, or conceived successfully at first insemination in first lactation $\left(r_{\mathrm{g}}=\right.$ 0.32) or had a longer interval between first and second calving $\left(r_{g}=0.17\right)$. Estimates of genetic correlations of reproductive performance with estimated 305-d milk
\end{abstract}

Received March 26, 2004.

Accepted June 3, 2004.

Corresponding author: B. L. Muir; e-mail: muir@cdn.ca. yield were different in magnitude, but similar in sign to those with persistency (0.02 to 0.51 ).

(Key words: genetic parameter, persistency, reproduction)

Abbreviation key: AFS = age at first insemination as a heifer (in days), $\mathbf{C D}=$ calving difficulty, $\mathbf{C I}=$ calving interval, MILK = estimated 305-d milk yield in first lactation, MTP = multiple-trait prediction, $\mathbf{N R R C}=$ nonreturn rate at $56 \mathrm{~d}$ after first insemination in first lactation, NRRH $=$ nonreturn rate at $56 \mathrm{~d}$ after first insemination as a heifer, PeakD = day in milk of peak milk yield.

\section{INTRODUCTION}

Poor fertility has been the predominant culling reason in first and second lactation (Pryce et al., 1997) and is an increasing concern in the dairy industry. Most reproductive performance traits are mainly influenced by management practices and other environmental factors, but recent work suggests that there is significant genetic variation in measures of female fertility (Weigel and Rekaya, 2000). Dairy producers would be able to capitalize on the benefits of increased milk production if advances in management or genetics lead to improvement of reproductive performance.

Increasingly, research indicates an undesirable relationship between milk yield and fertility (Pryce et al., 1997; Dematawewa and Berger, 1998; Abdallah and McDaniel, 2000). How total yield is spread throughout the lactation may influence this antagonistic relationship between yield and fertility. Persistency can be defined as the ability to maintain the level of milk production after peak milk yield. A possible way to increase total yields without increasing the occurrence of disease or reproductive failure is to select for increased lactation persistency in addition to total production. This selection strategy could be attempted by decreasing stressful peak yields and maintaining a high level of production after peak yield, thereby flattening and extending the lactation curve. The Wilmink function (Wil- 
mink, 1987) has been used in the past to model lactation curves and define persistency (Jamrozik et al., 1997; Schaeffer et al., 2000; van der Linde et al., 2000).

In general, producers breed cows as early as possible in lactation, believing that this strategy will enhance profitability. This management strategy forces higher producing cows to be inseminated when they are producing 45 to $50 \mathrm{~kg}$ daily (Arbel et al., 2001). Poor conception rates and reproductive inefficiency may contribute to the increasingly antagonistic relationship between yield and fertility that has been found (Pryce and Veerkamp, 2001).

Estimates of genetic parameters for persistency (Jamrozik et al., 1998; Rekaya et al., 2000; Van der Linde et al., 2000; Jakobsen et al., 2002) and fertility (Hoekstra et al., 1994; Pryce et al., 1997; Kadarmideen et al., 2000; Veerkamp et al., 2001) are abundant in the literature, as are relationships between fertility and milk production (Van Arendonk et al., 1989; Dematawewa and Berger, 1998; Veerkamp et al., 2001; HaileMariam et al., 2003). Investigation into relationships between persistency and reproductive performance is lacking. Therefore, the objective of this study was to estimate genetic relationships between lactation persistency and reproductive performance in first-lactation Holsteins. The timing and height of the lactation curve at peak yield have been suggested as alternative measures to persistency to genetically manipulate the shape of the lactation curve (Ferris et al., 1985). The genetic correlation between peak milk yield and 305-d milk yield was estimated to be high, and both traits had similar estimated genetic correlations with persistency and day of peak milk yield (Muir, 2004). In addition, 305 -d milk yield is a more widely used production trait. Therefore, day in milk of peak milk yield (PeakD) and estimated 305-d milk yield in first lacation (MILK) were selected as additional traits for analysis to relate with persistency and reproductive performance. The hypothesis was that cows with persistent lactations have better reproductive performance.

\section{MATERIALS AND METHODS}

\section{Data}

Three sources of data were obtained from the Canadian Dairy Network and combined: inseminations (1998 to 2003), calving data (1979 to 2003), and test day records (1990 to 2003). Insemination records from milk recording and AI centers were edited to exclude repeated inseminations within $15 \mathrm{~d}$ after first insemination to avoid double-counting inseminations for the same estrous cycle. The first recorded insemination on each animal was assumed to be the first insemination performed on that animal. Several heifer and first-lac- tation fertility traits were defined for this analysis. Age at first insemination as a heifer (AFS) was calculated as the number of days from birth to the first insemination performed on that animal. Nonreturn rate at $56 \mathrm{~d}$ after first insemination as a heifer (NRRH) and in first lactation (NRRC) were defined as 1 if there was no record of an insemination before $56 \mathrm{~d}$ after first insemination and 0 if there was a record of an insemination before $56 \mathrm{~d}$ after first insemination. These measures should reflect the animal's ability to conceive before and after first calving, respectively. Calving difficulty (CD) was scored subjectively by the producer and explained the amount of difficulty a heifer had giving birth. Scores ranged from 1 to 4, denoting unassisted or unobserved, easy pull, hard pull, and requiring surgery, respectively. Calving interval (CI) was calculated as the number of days from the first calving date to the second calving date.

Lactation data obtained from the Canadian Dairy Network were first-parity test day yields from lactations made between 1990 and 2003 by Canadian Holsteins. Days in milk ranged from 5 to $305 \mathrm{~d}$. Daily milk yield was required, but records with missing fat and protein yield were allowed. Lactations having the date of first test $>50 \mathrm{DIM}$ and/or average interval between tests $>50 \mathrm{~d}$ were excluded. Daily milk yields $>90 \mathrm{~kg}$ or $1.5 \mathrm{~kg}$ were also excluded to avoid possible erroneous data.

Fertility and production data were merged, and a sample of data was created by randomly selecting herds and then selecting all records within that herd for genetic parameter estimation. In doing so, approximately $50 \%$ of herds on milk recording were selected. To be included in the analysis, each heifer was required to have all reproductive performance traits of interest (AFS, NRRH, CD, NRRC, and CI) and, therefore, must survive until second calving. Routine collection of complete reproductive information has only recently been adopted in Canada; therefore, the oldest animals in the data set were born in 1995 . The final data set contained all 8 traits of interest on 33,312 first-lactation Holsteins.

\section{Models}

A multiple-trait prediction (MTP) procedure was used to estimate 305-d lactation yields from the individual milk, fat, and protein test day yields (Schaeffer and Jamrozik, 1996). The MTP method is based on Wilmink's function (Wilmink, 1987) and incorporates information about standard lactation curves and covariances between yields for milk, fat, and protein. Wilmink's model for one trait is 


$$
\mathrm{y}_{\mathrm{t}}=a+b \times \mathrm{t}+c \exp (-0.05 \times \mathrm{t})
$$

where $\mathrm{y}$ is yield on day $\mathrm{t}$ of lactation, $a$ is a regression coefficient related to the maximum daily level of production, $b$ is a regression coefficient related to production decrease after peak yield (persistency), $c$ is a regression coefficient related to production increase toward peak, and the factor 0.05 is related to the approximate DIM when peak milk yield occurs. Test day yields were weighted by their relative variances, and standard lactation curves of cows from similar breed, region, lactation, age at calving, and season of calving were used for the estimation of lactation curve parameters for each cow. For this study, only first lactations were considered. Using the 3 estimated Wilmink curve parameters for each animal, persistency, MILK, and PeakD for first lactation were also estimated. The definition of persistency selected for use in this study was the Wilmink b parameter, which was the estimated slope of the lactation curve after peak milk yield. This trait was chosen as a phenotypic measure of persistency because of its ease of calculation and moderate heritability (Muir, 2004) and its ability to be related with reproductive performance and other economically important traits on a large number of animals. In addition, this measure was easily computed with a software package currently used by milk-recording agencies to provide on-farm management information. The MILK was calculated by summing all estimated individual test day yields from d 5 to 305 DIM.

An 8-trait animal model was applied to calculate genetic parameters. Three production traits (persistency, PeakD, and MILK) and 5 reproductive performance traits (AFS, NRRH, CD, NRRC, and CI) constituted the 8 -trait analysis. In matrix notation, the model for the 8 traits can be written as

$$
\mathbf{y}=\mathbf{X b}+\mathbf{Z} \mathbf{a}+\mathbf{W p}+\mathbf{M q}+\mathbf{e}
$$

where $\mathbf{b}$ includes all fixed effects, $\mathbf{a}$ is a vector of additive genetic animal effects, $\mathbf{p}$ is a vector of herd within yearseason of birth effects, $\mathbf{q}$ is a vector of service sire or sire of calf effects, $\mathbf{e}$ is the vector of residual effects, and $\mathbf{X}, \mathbf{Z}, \mathbf{W}$, and $\mathbf{M}$ are the incidence matrices. Assume that

$$
\mathbf{y} \mid \mathbf{b}, \mathbf{a}, \mathbf{p}, \mathbf{q}, \mathbf{e} \sim \mathrm{N}(\mathbf{X b}+\mathbf{Z a}+\mathbf{W} \mathbf{p}+\mathbf{M q}, \mathbf{R})
$$

and

$$
\left(\begin{array}{l}
\mathbf{a} \\
\mathbf{p} \\
\mathbf{q} \\
\mathbf{e}
\end{array}\right) \sim \mathbf{N}(\mathbf{O}, \mathbf{V})
$$

with

$$
\mathbf{V}=\left(\begin{array}{cccccc}
\mathbf{G} \otimes \mathbf{A} & \mathbf{0} & \mathbf{0} & \mathbf{0} & \mathbf{0} & \mathbf{0} \\
\mathbf{0} & \mathbf{P} \otimes \mathbf{I} & \mathbf{0} & \mathbf{0} & \mathbf{0} & \mathbf{0} \\
\mathbf{0} & \mathbf{0} & \mathbf{Q}_{\mathbf{1}} \otimes \sigma_{\mathbf{q}_{1}}^{2} & \mathbf{0} & \mathbf{0} & \mathbf{0} \\
\mathbf{0} & \mathbf{0} & \mathbf{0} & \mathbf{Q}_{2} \otimes \sigma_{\mathbf{q}_{2}}^{2} & \mathbf{0} & \mathbf{0} \\
\mathbf{0} & \mathbf{0} & \mathbf{0} & \mathbf{0} & \mathbf{Q}_{3} \otimes \sigma_{\mathbf{q}_{3}}^{3} & \mathbf{0} \\
\mathbf{0} & \mathbf{0} & \mathbf{0} & \mathbf{0} & \mathbf{0} & \mathbf{R} \otimes \mathbf{I}
\end{array}\right)
$$

where $\mathbf{G}$ is a genetic covariance matrix $(8 \times 8)$ among traits, assumed to be the same for all heifers; $\mathbf{P}$ is a herd within year-season of birth covariance matrix (8 $\times 8$ ) among traits, assumed to be the same for all heifers; $\mathbf{A}$ is the additive genetic relationship matrix among the animals; $\otimes$ is Kronecker product function (Searle, $1982) ; \mathbf{R}$ is a residual covariance matrix $(8 \times 8)$ between traits; $\mathbf{Q}_{\mathbf{1}}, \mathbf{Q}_{\mathbf{2}}$, and $\mathbf{Q}_{\mathbf{3}}$ are matrices of zeros, with a 1 in the diagonal element corresponding to $\mathrm{NRRH}, \mathrm{CD}$, and NRRC, respectively; and $\sigma_{\mathrm{q} 1}{ }^{2},{\sigma_{\mathrm{q} 2}}^{2}$, and ${\sigma_{\mathrm{q} 3}}^{2}$ are the service sire effect for NRRH, sire of calf effect for CD, and service sire effect for NRRC variances, respectively.

Fixed and random effects included in the genetic models for each trait are shown in Table 1. Year of birth ranged from 1995 to 2000. Four seasons of calving were defined, December to February, March to June, July to September, and October to November. Age at first calving ranged from 19 to 36 mo. Random effect of herd within year-season of birth had 21,265 levels (5725 herds) and was included in all models to account for contemporary group effect properly. Year and season of birth was included as a fixed effect in every model to account for time trends. Random effect of service sire was included in the models for NRRH and NRRC, and these effects were assumed to be uncorrelated. Effect of sire of calf was included in the model for CD. Service sires and sires of calves were all assumed to be unrelated. Residuals were assumed to be uncorrelated. Although NRRH and NRRC were recorded as binary traits, and CD as a categorical trait, records for these traits were assumed to be normally distributed. It was assumed that there was no interaction between herd within year-season of birth and animal genetic effects. Covariances between effect of service sire and effects of sire of calf were assumed to be zero. All environmental factors not included the model were assumed to be the same for all records or contributed to the residual.

\section{Genetic Parameter Estimation}

Estimation of variances and covariances were achieved by Bayesian methods, similarly to Pool et al. (2000), utilizing the Gibbs sampler via the VCE 5 pack- 
Table 1. Effects included in the genetic models for genetic parameter estimation.

\begin{tabular}{|c|c|c|c|c|c|c|c|c|c|}
\hline \multirow[b]{2}{*}{ Trait $^{3}$} & \multicolumn{5}{|c|}{ Fixed effect ${ }^{1}$} & \multicolumn{4}{|c|}{ Random effect $^{2}$} \\
\hline & YS & MF & $\mathrm{ACMF}$ & $\mathrm{ACMC}$ & AFMCX & SS & $\mathrm{SC}$ & YS:H & Animal \\
\hline $\begin{array}{l}\text { AFS } \\
\text { NRRH } \\
\text { CD } \\
\text { NRRC } \\
\text { CI } \\
\text { Persistency } \\
\text { PeakD } \\
\text { MILK }\end{array}$ & $\begin{array}{l}0 \\
? \\
? \\
\bullet \\
? \\
? \\
? \\
0 \\
0\end{array}$ & $\stackrel{\bullet}{\bullet}$ & $\bullet$ & $\begin{array}{l}\bullet \\
\bullet \\
\bullet \\
\bullet\end{array}$ & $\bullet$ & $\begin{array}{l}\bullet \\
\bullet\end{array}$ & ○ & $\begin{array}{l}? \\
? \\
0 \\
0 \\
0 \\
? \\
? \\
0 \\
0 \\
0\end{array}$ & $\begin{array}{l}0 \\
? \\
? \\
\bullet \\
? \\
? \\
? \\
0\end{array}$ \\
\hline
\end{tabular}

${ }^{1} \mathrm{YS}=$ Year-season of birth, MF = calendar month of first insemination, ACMF = interaction of age at calving (mo) and calendar month of first insemination, ACMC = interaction of age at calving (mo) and calendar month of calving, and AFMFX = interaction of age at calving (mo) and calendar month of calving and sex of calf.

${ }^{2} \mathrm{SS}=$ Random effect of service sire, $\mathrm{SC}=$ random effect of sire of calf, and YS:H = random effect of herd within year-season of birth.

${ }^{3} \mathrm{AFS}=$ Age at first insemination as a heifer $(\mathrm{d}), \mathrm{NRRH}=$ nonreturn rate at $56 \mathrm{~d}$ after first insemination as a heifer, $\mathrm{CD}=$ difficulty at first calving, NRRC = nonreturn rate at $56 \mathrm{~d}$ after first insemination in first lactation, $\mathrm{CI}=$ interval between first and second calving, PeakD = DIM of peak milk yield; and MILK = estimated 305-d milk yield in first lactation.

age (Kovac et al., 2002). The VCE package utilizes a coupling method to assess the convergence of the Gibbs sampler to make marginal inferences with an animal model (García-Cortés et al., 1998). This coupling method is based on the output of 2 Markov chains with different starting values but the same conditional deviates. When the absolute maximum difference between variance ratios of 2 coupled chains neared a given tolerance $(0.01)$, the 2 chains were said to have converged, and burn-in was completed. After burn-in, the Gibbs sampler was set to perform 50,000 iterations.

Flat priors were assumed for all fixed effects. Inverted Wishart distributions were assumed for genetic, herd within year-season of birth, and residual covariances.
Starting values for all variances and covariances were found by compiling prior knowledge of the variances of all traits and assuming a correlation of 0.05 between all traits to derive covariances. The analysis was performed on 33,312 animals with records with a total of 96,218 pedigree animals.

Heritability was calculated as additive genetic variance $\left(\sigma^{2}{ }_{\mathrm{a}}\right)$ divided by phenotypic variance $\left(\sigma_{\mathrm{P}}^{2}\right)$, where $\sigma_{\mathrm{P}}^{2}=\sigma_{\mathrm{a}}^{2}+\sigma^{2} \mathrm{YS}: \mathrm{H}+\sigma^{2}{ }_{\mathrm{e}}$ for AFS, CI, persistency, PeakD, and MILK, and $\sigma_{\mathrm{P}}^{2}=\sigma_{\mathrm{a}}^{2}+\sigma_{\mathrm{YS}: \mathrm{H}}^{2}+\sigma_{\mathrm{SS} 1}^{2}, \sigma_{\mathrm{SC}}^{2}$, or $\sigma_{\mathrm{SS} 2}^{2}+$ $\sigma^{2}{ }_{\text {e }}$ for NRRH, NRRC, and CD, respectively, and where YS:H, SS1, SC, and SS2 were random effects of herd within year-season of birth, effect of service sire on $\mathrm{NRRF}$, effect of sire of calf on CD, and effect of service

Table 2. Descriptive statistics for data used to estimate variance components (selected data; $\mathrm{n}=33,312$ ) and the entire Canadian population (unselected data).

\begin{tabular}{lcccccc}
\hline & \multicolumn{2}{c}{ Selected data $(\mathrm{n}=33,312)$} & & \multicolumn{3}{c}{ Unselected data } \\
\cline { 2 - 3 } \cline { 6 - 6 } Trait $^{1}$ & Mean & $\mathrm{SD}$ & & $\mathrm{N}$ & Mean & SD \\
\hline AC (mo) & 27.27 & 2.36 & & $1,265,819$ & 27.42 & 3.39 \\
AFS (d) & 504.06 & 63.07 & & 477,748 & 508.67 & 67.45 \\
NRRH (\%) & 78.29 & 41.23 & & 476,433 & 76.05 & 42.16 \\
CD score & 1.60 & 0.69 & & 228,460 & 1.66 & 0.72 \\
Calving ease (\%) & 88.40 & 32.01 & & 228,460 & 86.11 & 34.58 \\
NRRC (\%) & 64.41 & 47.88 & & 267,833 & 61.98 & 48.54 \\
CI (d) & 395.41 & 50.19 & & 154,080 & 398.25 & 49.92 \\
Persistency (kg/d) & 0.04197 & 0.02184 & & $1,265,819$ & -0.03991 & 0.02234 \\
PeakD (d) & 57.55 & 37.04 & & $1,265,819$ & 54.37 & 41.40 \\
MILK (kg) & 7689.99 & 1405.37 & & $1,265,819$ & 7059.14 & 1582.30 \\
Peak milk yield (kg) & 31.35 & 5.18 & & $1,265,819$ & 29.36 & 5.55 \\
\hline
\end{tabular}

${ }^{1} \mathrm{AC}=$ Age at calving; AFS = age at first insemination as a heifer; $\mathrm{NRRH}=$ nonreturn rate at $56 \mathrm{~d}$ after first insemination as a heifer; $\mathrm{CD}=$ difficulty at first calving; calving ease $=$ number of scores of 1 or 2 divided by total number scored; NRRC = nonreturn rate at 56 days after first insemination in first lactation; $\mathrm{CI}=$ interval between first and second calving; PeakD = DIM of peak milk yield; and MILK = estimated 305-d milk yield in first lactation. 
sire on NRRC, respectively. Additive genetic correlations were calculated as $\sigma_{\mathrm{i}, \mathrm{j}} \div\left(\sigma_{\mathrm{i}} \times \sigma_{\mathrm{j}}\right)$, where $\sigma_{\mathrm{i}, \mathrm{j}}$ was the covariance between trait $\mathrm{i}$ and trait $\mathrm{j}$, respectively, and $\sigma_{\mathrm{i}}$ and $\sigma_{\mathrm{j}}$ were the standard deviations of trait $\mathrm{i}$ and trait $\mathrm{j}$, respectively.

\section{RESULTS AND DISCUSSION}

\section{Descriptive Statistics}

Means and summary statistics are presented in Table 2. Average peak daily milk yield and MILK were 31.35 and $7689 \mathrm{~kg}$, respectively, in first lactation. Lean et al. (1989) reported an average peak daily milk yield of $37.36 \mathrm{~kg}$. Average PeakD was $57 \mathrm{~d}$ in first lactation. Lean et al. (1989) reported an average DIM at peak of $69 \mathrm{~d}$ for all lactations combined. Average AFS was 504 $\mathrm{d}$, which was similar to the average of $508 \mathrm{~d}$ in the Canadian Holstein population. Average NRRH and NRRC in this study was 78 and $64 \%$, respectively, which was higher than other estimates (Hoekstra et al., 1994), but similar to the Canadian average. As animals age, conception rates decline. Therefore, NRRC should be lower than NRRH. To be included in this analysis, animals had to survive until second calving; therefore, this selected population was expected to have slightly higher conception rates in first lactation compared with the Canadian population. An average CI of $395 \mathrm{~d}$ was found in this study, which was very similar to previous reports (Pryce et al., 1997; Veerkamp et al., 2001). Average CD score was 1.6 , on a scale from 1 to 4 , with 4 indicating severe dystocia. On a population basis, it is more logical to express calving ease as a percentage, specifically number of scores of 1 or 2 (unassisted or easy pull) divided by total scores recorded (1, 2, 3, or 4), where a higher percentage would indicate fewer calving difficulties. Average calving ease expressed in this way was $88.4 \%$. This average was slightly higher than that found in the entire Canadian population for first-calf Holsteins $(86.1 \pm 34.9)$. Selected animals were slightly more persistent and better producers than the average Canadian Holstein.

\section{Heritability Estimates}

Heritabilities of reproductive performance were low (Table 3) and ranged from 0.03 to 0.19 . The most heritable reproductive trait was AFS. Heritability of CD was 0.16 . Luo et al. (2001) reported a similar estimate of heritability of CD of 0.12 . Heritability of CI was low (0.07), which was consistent with previous estimates (Hoekstra et al., 1994; Pryce et al., 1997; Veerkamp et al., 2001; Haile-Mariam et al., 2003; Kadarmideen et al., 2003). This trait can be highly influenced by the length of the voluntary waiting period and if synchroni-

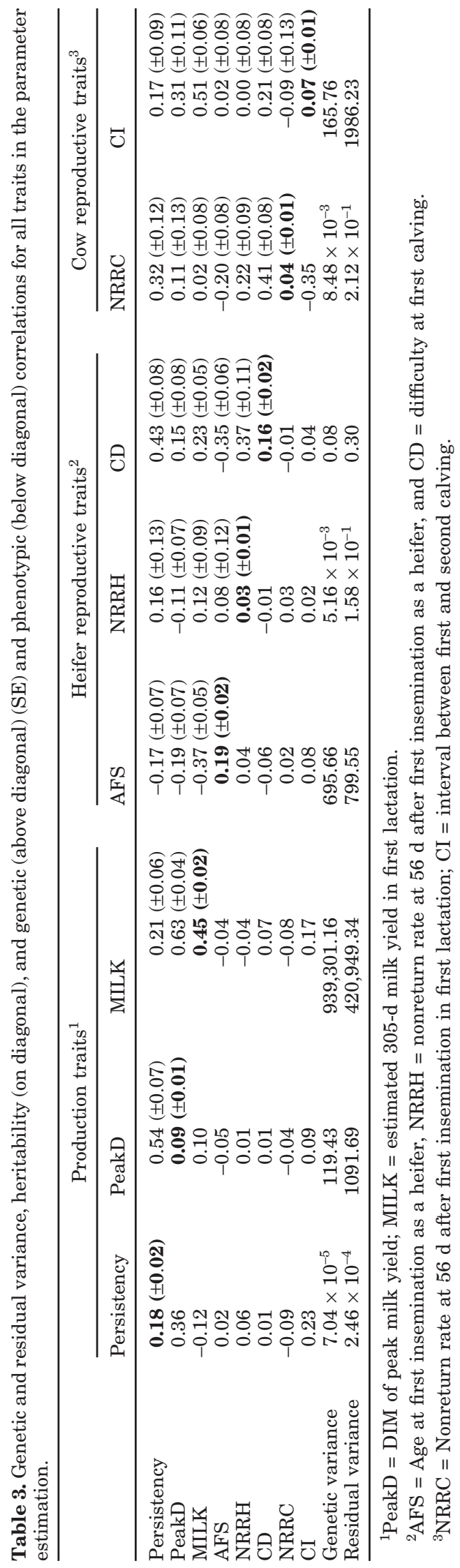

Journal of Dairy Science Vol. 87, No. 9, 2004 
zation products have been used, which would inflate environmental variance. Heritabilities of NRRH and NRRC were 0.03 and 0.04 , respectively. Hoekstra et al. (1994) and Ranberg et al. (2003) reported similar estimates. Differences in heritability of heifer and cow nonreturn rate at $56 \mathrm{~d}$ were negligible in this study. Jansen (1986) reported the heritability of nonreturn rate at $56 \mathrm{~d}$ to be 2.1 and $2.4 \%$ in first and later parities, respectively.

Heritability of persistency, PeakD, and MILK are shown in Table 3. Heritability of persistency was 0.18 and was equal to the estimate reported by Van der Linde et al. (2000) using similar methodology. Heritability of lactation persistency in first lactation, calculated as a by-product of random regression modeling of test day yields, has been much higher at 0.30 (Jamrozik et al., 1998). Heritability of MILK was 0.45 , which was much higher than the heritability of persistency. Estimates of heritability of 305-d milk yield in Canada have been similar to the results found here using different models (Batra et al., 1987b; Schaeffer et al., 2000). Other estimates for heritability of 305-d MILK estimated using MTP were not available in the literature. Heritability of PeakD was low (0.09). Ferris et al. (1985) reported the heritability of timing of peak yield to be 0.07 , and PeakD was much less heritable than persistency. Therefore, PeakD would not perform as well as persistency as an indicator trait for genetically improving the shape of the lactation curve.

\section{Genetic Correlations Between Reproductive Performance Traits}

Estimated genetic correlations between reproductive performance traits were variable and lower (range = 0.50 to 0.78 ) than other recently reported estimates (Pryce et al., 1997; Dematawewa and Berger, 1998; Kadarmideen et al., 2003). Estimated genetic correlation between the 2 heifer reproductive performance traits (AFS and NRRH) was small and positive $(0.08 \pm 0.12)$ with a large standard error, indicating that the age of the animal when it is first inseminated had little or nothing to do with conception success at that insemination. Estimated genetic correlation of AFS with NRRC was negative and stronger than that with NRRH $(-0.20$ \pm 0.08 ), indicating that heifers younger than average when first inseminated (that came into estrus for the first time earlier in life) tended to have a better chance of conceiving at first insemination after first calving. Estimated genetic correlation between NRRH and NRRC was only moderately positive, indicating that conception success as a virgin heifer could not accurately predetermine conception success as a first lactation cow and that different genetic and physiological determination of fertility between parities may exist. Batra et al. (1987b) showed that genetic correlations between heifer fertility and cow fertility were close to zero, indicating that heifer and cow fertility seem to be genetically independent. Nonreturn rate as a heifer and as a first lactation cow (NRRH and NRRC) were genetically unrelated to CI.

Moderate relationships existed between $\mathrm{CD}$ and other reproductive traits. Heifers younger than average when first inseminated tended to have greater dystocia at first calving $\left(r_{g}=-0.35 \pm 0.06\right)$. First-lactation cows that had greater $\mathrm{CD}$ also tended to conceive more successfully at first insemination after calving $\left(r_{g}=0.41\right.$ \pm 0.08 ). A longer CI was genetically associated with a more difficult first calving. Perhaps breeding of difficult calving heifers was delayed until after stressful high peak milk yields, when a successful insemination would be more probable and lactations were subsequently prolonged longer than average. Kadarmideen et al. (2000) reported that genetic correlations between dystocia and other reproductive traits were close to zero.

\section{Genetic Correlations Between Production Traits}

Estimated genetic correlation between PeakD and persistency was $0.54( \pm 0.07)$, indicating that as the interval from initiation of lactation to peak yield increased and persistency improved. Selection on one trait should improve the other, but only moderately so. Other researchers have found the genetic correlation between persistency and timing of peak yield to be positive and high (Batra et al., 1987b; Rekaya et al., 2000) and some to be positive and moderate (Ferris et al., 1985). The PeakD was also positively genetically correlated with MILK $(0.63 \pm 0.06)$, indicating that as total lactation yield increased, so did the interval from initiation of lactation to peak yield.

Estimated genetic correlation between MILK and persistency in first lactation was $0.21( \pm 0.06)$ and was higher than expected. Several researchers have found correlations (positive and negative) of persistency with 305 -d yield ranging from 0 to over 0.60 , varying with the way persistency was defined (Ferris et al. 1985; Jamrozik et al., 1998; Rekaya et al., 2000; van der Linde et al., 2000; Jakobsen et al., 2002). Gengler (1996) recommended the use of a measure of persistency that is genetically independent of 305-d milk yield; however, in this study, a small positive genetic correlation was estimated between yield and persistency, indicating that selection for increased MILK would slightly improve persistency. Clearly, relationships exist between the shape of the lactation curve and total production. Minimizing this relationship will allow more efficient 
selection for total lactation yield and persistency simultaneously.

\section{Genetic Correlations Between Reproduction and Production}

Estimated genetic correlations between reproduction traits and persistency ranged from 0.17 to 0.43 (Table $3)$. Age at first insemination was negatively correlated with persistency $(-0.17 \pm 0.07)$, indicating that heifers that were younger when first inseminated tended to have better persistency in first lactation. The correlation between persistency in first lactation and NRRH was positive $(0.16 \pm 0.13)$ but had a large standard error, so caution should be used when making statements about this possible relationship. Reproductive performance as a virgin heifer could indicate future shapes of lactation curves, and these relationships should be further investigated. Lean et al. (1989) reported that cows with higher than average peak milk yields and poorer than average persistency were less likely to conceive in 1 or 2 services. Bar-Anan et al. (1985) defined persistency as average daily yield divided by peak yield and found that cows with higher lactation persistency had better reproductive performance. Haile-Mariam et al. (2003) reported the absence of genetic antagonism between fertility and persistency. Nonreturn rate at $56 \mathrm{~d}$ after first insemination in first lactation was also positively correlated with persistency $(0.32 \pm 0.12)$, indicating that first lactation cows that tended to conceive on first insemination also tended to have better persistency.

The genetic correlation between CI and persistency was estimated to be $0.17( \pm 0.09)$. As expected, the greater persistency was in first lactation, the longer the interval was from first to second calving. Longer CI are generally viewed as undesirable; therefore, genetically an antagonistic relationship existed between persistency and CI in first lactation. However, Arbel et al. (2001) reported that there was an economic advantage to extending lactations by $60 \mathrm{~d}$ in high yielding dairy heifers in first lactation. Stott et al. (1999) reported that the marginal value for CI at the optimum estrous detection rate was $\$ 11.75 / \mathrm{d}$ rising to $\$ 14.06 / \mathrm{d}$ if breeding was delayed.

The estimated genetic correlation between $\mathrm{CD}$ and persistency was strong $(0.43 \pm 0.08)$. Heifers that had a difficult first calving tended to have more persistent first lactations. Heifers that had difficulty calving would also tend to have lower peak yields, possibly causing the antagonistic relationship between CD and persistency. Previously, speculation was made that heifers with greater CD may have longer intervals from calving to first insemination, and, therefore, fertility would be better later in lactation after peak milk yield. If this were true, one would expect the correlation between CI and persistency to be $>0.17$. To test this hypothesis, DIM at insemination could be included as a covariate in the model for CI and correlated with persistency in a bivariate animal model or number of days from calving to first insemination could be included as a correlated trait in a multiple trait animal model. Alternatively, one could speculate that persistency is genetically correlated with less severe early lactation negative energy balance. Higher persistency appears to be positively correlated with later DIM at peak milk yield and lower peak yield (Ferris et al., 1985), both of which are indicators of less severe negative energy balance. Veerkamp et al. (2000) reported that the interval from calving to first service decreased when negative energy balance was less severe.

Estimated genetic correlations between reproductive performance and PeakD ranged from 0.11 to 0.31 (Table 3 ). The strongest genetic correlation was between CI and PeakD and suggested that the longer into lactation an animal experienced peak daily milk yield, the longer the interval was between first and second calving. A negative genetic relationship between AFS and PeakD existed and indicated that heifers that were younger when first inseminated tended to have a later peak yield in first lactation. Heifers that were younger when first inseminated also tended to have better persistency. Later peak yields were genetically associated with better persistency, so these two estimated genetic correlations were expected. Cows that had difficulty calving tended to have a later PeakD $\left(r_{g}=0.15 \pm 0.08\right)$.

Estimated genetic correlations between reproductive performance and MILK were similar in sign, but different in magnitude, to those with persistency. The strongest genetic correlation existed between MILK and CI and indicated that a longer CI was associated with greater MILK in first lactation $(0.51 \pm 0.11)$. Similar genetic correlations have been reported between CI and MILK in the literature, ranging from 0.23 to 0.67 (Hoekstra et al., 1994; Veerkamp et al., 2001; Haile-Mariam et al., 2003; Kadarmideen et al., 2003).

The estimated genetic correlation between AFS and MILK was $-0.37( \pm 0.05)$ and indicated that heifers that were younger when first inseminated tended to have greater MILK in first lactation. Heifers that were younger when first inseminated probably came into heat for the first time earlier in life and therefore showed a greater propensity to mature. Genetic ability to mature faster and reach a greater proportion of their mature body weight at an earlier age may have been the biological driving force causing AFS to be genetically correlated to greater total yield expected in first lactation. Early maturing heifers with a lower AFS also 
had better persistency and later peak yields in first lactation. Cow fertility (NRRC) was uncorrelated with MILK. Other estimates of genetic correlations of MILK with conception success in the literature have been much stronger (Hoekstra et al., 1994; Veerkamp et al., 2001). Correlations between persistency and conception success were stronger than those found with MILK. Therefore, conception success as a first-lactation cow tended to be more related to the dispersion of yield in first lactation rather than total yield.

Age at first insemination was moderately heritable and negatively genetically correlated with persistency and with MILK. Therefore, selecting heifers that come into heat for the first time at a younger age could improve persistency and MILK in first lactation. Heifers inseminated at a younger age also tended to have better conception success (NRRC) in first lactation. However, an unfavorable correlation between AFS and CD existed. Selecting for earlier AFS may result in improved persistency, 305-d yield, and NRRC, but early maturing heifers may need to be mated to calving ease sires to decrease dystocia at first calving.

A positive estimated genetic correlation was shown between CI and persistency in first lactation. Possibly, first-lactation heifers that were open longer would seem to be more persistent because they would be directing less energy toward the unborn calf. Additionally, low persistency could have been detrimental to conception after first calving. However, the estimated genetic correlation between persistency and NRRC was 0.32 and indicated that conception success at first insemination after calving tended to be related to better persistency in first lactation. More persistent lactations were somewhat associated with higher $305-d$ yields. Perhaps insemination of first-lactation cows that experienced dystocia was delayed longer than average, possibly long after stressful peak yields, and, therefore, better conception success resulted. Having data available on the exact number and timing of all inseminations and conception rates for each insemination, in addition to having the reasons for and length of voluntary waiting periods, would help assign cause and effect to some of these relationships.

Several researchers have shown a consistently antagonistic relationship between reproductive performance and milk yield. In addition, studies show that genetically, persistency can vary with total yield; minimizing this relationship will allow for more effective selection of total yield and shape of lactation curves. Prior to conducting this study, research lacked investigation into how these relationships all fit together, i.e., the relationships between reproductive performance and persistency, under conditions of continuous selection for milk yield.
In this study, persistency, MILK, and PeakD were calculated by fitting lactation curves to phenotypic test day yields for individual cows (using MTP) and were not directly observed, which might have resulted in less accurate estimates of covariance components for these traits. Using a hierarchical model (Rekaya et al., 2000) or a random regression test day model to estimate lactation curve parameters directly (Jamrozik et al., 1997) would properly account for all covariances among observations (test days), which should improve the accuracy of the estimates of covariance components. Once genetic parameters of lactation curves are estimated, relationships among PeakD, persistency, and MILK could be derived analytically.

Some differences in estimated relationships between reproductive performance and persistency exist between these results and those that have been previously reported (Bar-Anan et al., 1985; Lean et al., 1989; HaileMariam et al., 2003). In this study, heifers were required to have all 5 reproductive performance traits recorded (and therefore survive to a second calving). Selection of data in this way might have been biased toward healthy, more fertile heifers, as the poorest heifers (in terms of health and fertility) were probably culled before being able to calve for a second time. Although means for the selected data set in this study were similar to those of the entire Canadian population (Table 2), selection bias might have affected genetic parameter estimates. The magnitude of this bias was not quantified but was expected to be minimal. Estimates of heritability of reproductive traits found in this multiple-trait analysis using a selected population were nearly identical to single trait estimates found using an unselected data set and similar models (Fatehi, personal communication, 2003). Selection bias could be avoided by creating a data set allowing for the possibility of missing observations for fertility traits. Computational packages that allow for missing observations and complicated covariance structures on a large number of animals should be investigated for calculation of genetic parameters for several fertility traits simultaneously with production traits. Persistency was defined differently here, than in the previously mentioned studies and might have contributed to some differences found. Only first lactation was investigated in this study. Relationships between persistency and fertility in later lactations may be different than those found here in first lactation and should be investigated further.

\section{CONCLUSIONS}

Heifers that showed signs of estrus for the first time earlier than average and, therefore, were inseminated for the first time early in life tended to have more diffi- 
cult first calvings, but had later peak yields, greater total 305-d yields, and greater persistency in first lactation. Higher nonreturn rate at first service in first lactation was associated with increased persistency. Higher 305-d yields and greater persistency were associated with a longer CI. Selection for persistency of lactation seems to have merit for genetically improving reproductive performance in first lactation while selection for total yield continues.

\section{ACKNOWLEDGMENTS}

The authors thank the National Sciences and Engineering Research Council, Agriculture and Agri-Food Canada, Ontario Ministry of Agriculture and Food, and the Dairy Cattle Genetics Research and Development Council for funding.

\section{REFERENCES}

Abdallah, J. M., and B. T. McDaniel. 2000. Genetic parameters and trends of milk, fat, days open, and body weight after calving in North Carolina experimental herds. J. Dairy Sci. 83:1364-1370.

Arbel, R., Y. Bigun, E. Ezra, H. Sturman, and D. Hojman. 2001. The effect of extended calving intervals in high-yielding cows on milk production and profitability. J. Dairy Sci. 84:600-608.

Bar-Anan, R. M., and G. R. Wiggans. 1985. Associations among milk yield, yield persistency, conception and culling of Israeli Holstein dairy cattle. J. Dairy Sci. 68:382-386.

Batra, T. R., A. J. Lee, and A. J. McAllister. 1987a. Relationships of reproductive performance, body weight and milk yield in dairy cattle. Can. J. Anim. Sci. 66:53-62.

Batra, T. R., C. Y. Lin, A. J. McAllister, A. J. Lee, G. L. Roy, J. A. Vesely, J. M. Wauthy, and K. A. Winter. 1987b. Multitrait estimation of genetic parameters of lactation curves in Holstein heifers. J. Dairy Sci. 70:2105-2111.

Dematawewa, C. M. B., and P. J. Berger. 1998. Genetic and phenotypic parameters for 305-day yield, fertility, and survival in Holsteins. J. Dairy Sci. 81:2700-2709.

Ferris, T. A., I. L. Mao, and C. R. Anderson. 1985. Selecting for lactation curve and milk yield in dairy cattle. J. Dairy Sci. 68:1438-1448

García-Cortés, L. A., M. Rico, and E. Groeneveld. 1998. Using coupling with the Gibbs sampler to assess convergence in animal models. J. Anim. Sci. 76:441-447.

Gengler, N. 1996. Persistency of lactation yields: A review. Proc. international workshop on genetic improvement of functional traits in cattle, Gembloux, Belgium. Interbull Bull. 12:87-96.

Haile-Mariam, M., P. J. Bowman, and M. E. Goddard. 2003. Genetic and environmental relationships among calving interval, survival, persistency of milk yield and somatic cell count in dairy cattle. Livest. Prod. Sci. 80:189-200.

Hoekstra, J., A. W. van der Lugt, J. H. J. van der Werf, and W. Ouweltjes. 1994. Genetic and phenotypic parameters for milk production and fertility traits in upgraded dairy cattle. Livest. Prod. Sci. 40:225-232.

Jakobsen, J. H., P. Madsen, J. Jensen, J. Pedersen, L. G. Christensen, and D. A. Sorensen. 2002. Genetic parameters for milk production and persistency for Danish Holsteins estimated in random regression models using REML. J. Dairy Sci. 85:1607-1616.

Jamrozik, G., J. Jansen, L. R. Schaeffer, and Z. Liu. 1998. Analysis of persistency of lactation calculated from a random regression test day model. Interbull Bull. 17:64-69. Rotorua, New Zealand. Available: http://www-interbull.slu.se/bulletins/bulletin17/ Jamrozik.pdf. Accessed Feb. 30, 2004.
Jansen, J. 1986. Direct and maternal genetic parameters of fertility traits in Friesian cattle. Livest. Prod. Sci. 15:153-164.

Kadarmideen, H. N., R. Thompson, M. P. Coffey, and M. A. Kossaibati. 2003. Genetic parameters and evaluations from single- and multiple-trait analysis of dairy cow fertility and milk production. Livest. Prod. Sci. 81:183-195.

Kadarmideen, H. N., R. Thompson, and G. Simm. 2000. Linear and threshold model genetic parameters for disease, fertility and milk production in dairy cattle. Anim. Sci. 71:411-419.

Kovac, M., E. Groeneveld, and L. A. García-Cortés. 2002. VCE-5. A package for the estimation of dispersion parameters. In Proc. 7th WCGALP, CD ROM, Communication No. 28-06.

Lean, I. J., J. C. Galland, and J. L. Scott. 1989. Relationships between fertility, peak milk yields, and lactation persistency in dairy cows. Theriogenology 31:1093-1103.

Luo, M. F., P. J. Boettcher, L. R. Schaeffer, and J. C. M. Dekkers. 2001. Bayesian inference for categorical traits with an application to variance component estimation. J. Dairy Sci. 84:694-704.

Muir, B. L. 2004. Genetic of lactation persistency and relationships with reproductive performance in Holsteins. Ph.D. Dissertation. Univ. Guelph, ON, Canada.

Pool, M. H., L. L. G. Janss, and T. H. E. Meuwissen. 2000. Genetic parameters of Legendre polynomials for first parity lactation curves. J. Dairy Sci. 83:2640-2649.

Pryce, J. E., and R. F. Veerkamp. 2001. The incorporation of fertility indices in genetic improvement programs. Pages 237-250 in Fertility in the High-Producing Dairy Cow, Vol. 1. M. G. Diskin, ed. Br. Soc. Anim. Sci., Occasional Publication No. 26. Penicuik, UK.

Pryce, J. E., R. F. Veerkamp, R. Thompson, W. G. Hill, and G. Simm. 1997. Genetic aspects of common health disorders and measures of fertility in Holstein Friesian dairy cattle. Anim. Sci. 65:353360

Ranberg, I. M. A., B. Heringstad, G. Klemetsdal, M. Svendsen, and T. Steine. 2003. Heifer fertility in Norwegian dairy cattle: Variance components and genetic change. J. Dairy Sci. 86:2706-2714.

Rekaya, R., M. J. Carabano, and M. A. Toro. 2000. Bayesian analysis of lactation curves of Holstein-Friesian cattle. J. Dairy Sci. 83:2691-2701.

Schaeffer, L. R., and J. Jamrozik. 1996. Multiple-trait prediction of lactation yield for dairy cows. J. Dairy Sci. 79:2044-2055.

Schaeffer, L. R., J. Jamrozik, G. J. Kistemaker, and B. J. Van Doormaal. 2000. Experience with a test-day model. J. Dairy Sci. 83:1135-1144.

Searle, S. R. 1982. Matrix Algebra Useful for Statisticians. John Wiley \& Sons, Inc., New York, NY.

Stott, A. W., R. F. Veerkamp, and T. R. Wassell. 1999. The economics of fertility in the dairy herd. Anim. Sci. 68:49-57.

Van der Linde, R., A. Groen, and G. de Jong. 2000. Estimation of genetic parameters of milk production in dairy cattle. Proceedings of the 2000 Interbull Meeting in Bled, Slovenia, May 14-15, 2000. Interbull Bull. 25:113-116. Available: http://www-interbull. slu.se/bulletins/bulletin25/van_der_Linde.pdf. Accessed Nov. 10,2003

Vanarendonk, J. A. M., R. Hovenier, and Willem De Boer. 1989. Phenotypic and genetic association between fertility and production in dairy cows. Livest. Prod. Sci. 21:1-12.

Veerkamp, R. F., E. P. C. Koenen, and G. De Jong. 2001. Genetics correlations among body condition score, yield, and fertility in first-parity cows estimated by random regression models. J. Dairy Sci. 84:2327-2335.

Veerkamp, R. F., J. K. Oldenbroek, H. J. Van Der Gaast, and J. H. J. Van Der Werf. 2000. Genetic correlations between days until start of luteal activity and milk yield, energy balance and live weights. J. Dairy Sci. 83:577-583.

Weigel, K. A., and R. Rekaya. 2000. Genetic parameters for reproductive performance of Holstein cattle in California and Minnesota. J. Dairy Sci. 83:1072-1080.

Wilmink, J. B. M. 1987. Adjustment of test-day milk, fat and protein yield for age, season and stage of lactation. Livest. Prod. Sci. $16: 335-348$ 